\title{
AFP Case Detection Along International Border Communities in Oyo State: Challenges, Opportunities and Threats
}

\author{
Bassey Enya Bassey, Fiona Braka, Sisay Gashu Tegene, Gerald Sume, Rosemary Onyibe, \\ Olufunmilola Olawumi Kolude, Marion Mosunmola Osanoto, Leonard Idemudia Ugheighele, \\ Ayomide Oluwaseyi Aibinuomo, Joy Ogechi Max-Ikechebelu, Olayiwola Suliat Olanike, \\ Angela Ugochukwu Okocha-Ejeko
}

World Health Organization, Country Representative Office, Abuja, Nigeria

Email address:

Bassey69@yahoo.com (B. E. Bassey)

\section{To cite this article:}

Bassey Enya Bassey, Fiona Braka, Sisay Gashu Tegene, Gerald Sume, Rosemary Onyibe, Olufunmilola Olawumi Kolude, Marion Mosunmola Osanoto, Leonard Idemudia Ugheighele, Ayomide Oluwaseyi Aibinuomo, Joy Ogechi Max-Ikechebelu, Olayiwola Suliat Olanike, Angela Ugochukwu Okocha-Ejeko. AFP Case Detection Along International Border Communities in Oyo State: Challenges, Opportunities and Threats. Science Journal of Public Health. Vol. 9, No. 3, 2021, pp. 103-108. doi: 10.11648/j.sjph.20210903.17

Received: March 16, 2021; Accepted: March 29, 2021; Published: May 26, 2021

\begin{abstract}
A weak AFP surveillance system constitutes a major threat to Nigeria's polio free certification status. This study investigates the factors that have affected AFP surveillance, case detection along the international border settlements of Oyo state, Nigeria. A cross-sectional survey was conducted between $26^{\text {th }}-31^{\text {th }}$ December 2018 using structured questionnaires uploaded onto Open Data Kit-collect (ODK) mobile software in 4 LGAs in Oyo state. Overall, 427 respondents (community members $=420$, community informants $=7$ ) participated in this study. On the average, $10 \%$ and $46 \%$ of the community members and informants could identify the various aspects of the AFP case definition. Majority of the community members weren't aware of AFP surveillance neither were they aware of their AFP focal person/DSNO or where to report AFP cases. Barriers to case reporting include, irregular movements of commercial vehicles, swampy roads during rainy seasons, rocky roads during dry seasons; poor communication networks; and poor modes of transportation. The accessibility and difficulty of terrain along these international boarders has greatly hindered surveillance activities in their corresponding communities. If steps are taken to improve accessibility in such areas, we believe that AFP case detection and reporting would also improve.
\end{abstract}

Keywords: Acute Flaccid Paralysis, Surveillance, International Border Communities

\section{Introduction}

Four of the six World Health Organization regions have been certified as polio free nearly 3 decades after the World Health Assembly launched the Global Polio Eradication Initiative (GPEI) in 1988. [1, 2] Nigeria, Afghanistan and Pakistan remain the only countries without a polio free certification.[3, 4] Nigeria was readmitted to the list of polio endemic countries following the August 2016 incident where four WPV1 was discovered in Borno state. [1] Though no new cases of WPV have been reported, Nigeria continues to implement prompt response strategies to ensure that the August 2016 scenario does not repeat itself.

To halt the transmission of polio in an area, the WHO recommends a four-part eradication strategy: routine immunization (RI) of infants less than 1 year old with at least three doses of oral polio virus vaccine (OPV), the administration of supplemental doses of OPV to all children under the age of 5 years during National Immunization Days to decrease the widespread circulation of the polio virus rapidly, localized 'mopping up' vaccination campaigns $\mathrm{s}$ and a highly sensitive AFP surveillance system. [5-7]

AFP surveillance remains the gold standard for polio eradication and it underpins the entire eradication initiative [8-10]. It is impossible to prove the interruption of the wild polio virus without good-quality AFP surveillance An AFP surveillance system must be sensitive enough to pick at least three AFP cases per 100,000 children below 15 years of age. For all AFP cases reported, adequate stool samples must be 
collected and transported to a World Health Organization (WHO) accredited laboratory via a reverse cold-chain transport system for polio enterovirus isolation. [11, 12] Adequate stool sample collection occurs when two stool samples are collected 24 hours apart within 14 days of paralysis onset and arrive at the laboratory within 72 hours from when the first stool sample was collected $[3,13]$

However, AFP surveillance network is skewed to health facilities in urban and semi urban areas while special population e.g. nomadic, hard-to-reach settlements are neglected resulting in under-reporting of AFP cases. [14] Oyo state for example has certain communities that share international boundaries with countries like the Republic of Benin. The Local Government Areas (LGAs) in the state, which share these boundaries, are Atisbo, Saki West, Iwajowa and Itesiwaju with a total population of 926,694 people.

An AFP surveillance situation analysis indicated that no case of AFP had been reported in these LGAs in the last 4 years. This indicates weakness in the AFP surveillance system. Therefore, this study aims to investigate the factors that affect AFP case detection along the international border settlements, identify challenges, threats and opportunities that can be used to improve the surveillance system in general.

\section{Methods}

\section{Study Location}

This study was carried in Oyo State. The state is one of the six states in the Southwest geopolitical zone of Nigeria. The State had a total projected population of $8,351,831$ people in 2018 from the 2006 census with annual target populations of 1,670,366 (children under 5 years) and 334,073 (Under 1 year). Oyo state comprises 33 Local Government Areas (LGAs) with Atisbo, Itesiwaju, Iwajowa and Saki west being the LGAs of focus in this study.

Atisbo, Itesiwaju, Iwajowa and Saki West LGAs has 10 wards respectively with average of 8 AFP focal sites per LGA and 35 Community Informants per LGA.

\section{Study population}

Study population included two groups of respondents; Community Informants and Community members. For community members, 428 (Atisbo 73, Iwajowa 115, Itesiwaju 132, Saki West 108) respondents while Community Informants is 7 (Atisbo 1, Iwajowa 3, Itesiwaju 2, Saki West
1). Total study population, $\mathrm{n}=435$.

\section{Study design}

A cross-sectional survey was conducted between $26^{\text {th }}-31^{\text {th }}$ December 2018 using structured questionnaires uploaded onto Open Data Kit-collect (ODK) mobile software in 4 LGAs in Oyo state.

Two questionnaires were developed for the purposes of this study. The questionnaires were administered to the community informants living in the boarder settlement) and the respondents at the community level.

\section{Inclusion and exclusion criteria}

Atisbo, Itesiwaju, Iwajowa and Saki West LGAs were selected based on their location at the International boarder to the Republic of Benin. In Total, 17 settlements were visited across the 4 LGAs (Atisbo 6, Itesiwaju 4, Iwajowa 4, Saki West 3). Community members were selected from each settlement using simple random or systematic sampling methods.

\section{Ethical consideration}

Ethical approval for this research will be obtained from the Oyo State Ministry of Health Research and Ethics Review Committee. Verbal informed consent will obtained from each respondent (Parent/caregiver) before the interview. Respondent's confidentiality will be maintained by using identification number and not name.

\section{Data Collection tools and techniques}

The standardized questionnaires were used for face-to-face interviews in the communities. Responses were collected in real-time using ODK with the assistance of research assistants. The structured interviews were conducted with a sample of 428 community member and 7 Community Informants living at the boarder settlements Unstructured interviews, using in-depth and open-ended questions, were conducted with Disease surveillance and Notification Officers (DSNOs) at the 4 LGAs. Our aim was to uncover each DSNO's views on constraints on AFP surveillance and opportunities for improving AFP detection in these areas.

\section{Data analysis/ Reliability and Validity of Data}

Geospatial analyses were conducted to know the exact location of respondents. Data will be analyzed using SPSS version 25.0. Analyses will include frequency and percent distributions. Cross tabulation will be used to check interference of socio demographic variables across the dependent variable.

\section{Results}

Table 1. Awareness of Community members /Informants on AFP surveillance.

\begin{tabular}{|c|c|c|}
\hline Variables & Yes $(\%)$ & No $(\%)$ \\
\hline Are community members aware/sensitized of AFP surveillance $(n=428)$ & $8(2)$ & $420(98)$ \\
\hline Do community members know their AFP focal person or DSNO $(n=420)$ & $8(2)$ & $420(98)$ \\
\hline Do community members know where to report a suspected AFP case? $(n=420)$ & $11(3)$ & $417(97)$ \\
\hline Do members of the community have contact numbers of focal person/DSNO? $(n=420)$ & $7(2)$ & $421(98)$ \\
\hline Are the informants aware of AFP surveillance $(n=7)$ & $7(100)$ & $0(0)$ \\
\hline Do the informants know that all cases of AFP must be reported $(n=7)$ & $6(86)$ & $1(14)$ \\
\hline Must all cases of AFP be reported to the Disease surveillance and notification officer (DSNO) $(n=7)$ & $7(100)$ & $0(0)$ \\
\hline Have community informants received training on AFP surveillance in the last year $(n=7)$ & $7(100)$ & $0(0)$ \\
\hline
\end{tabular}


Table 2. Barriers to AFP Reporting.

\begin{tabular}{lc}
\hline Variables & Frequency (\%) \\
\hline Ever reported AFP Cases in the Last 6 months (n=7) & $7(100)$ \\
No & $0(0)$ \\
Yes & $7(100)$ \\
Reasons for not Reporting (multiple response) $(\mathrm{n}=7)$ & $7(10)$ \\
Have not seen a case of AFP & $7(100)$ \\
Bad road terrain (irregular movements of commercial vehicles, swampy roads during rainy season, rocky roads during dry season) \\
Poor communication network & $7(100)$ \\
Modes of transportation (four wheel drive) & $4(57)$ \\
Do you receive regular feedback/update on AFP surveillance activities $(\mathrm{n}=7)$ & $3(43)$ \\
No & \\
Yes & \\
Do you receive incentive for reporting AFP cases (n=7) & $5(71)$ \\
No & $2(29)$ \\
\hline
\end{tabular}

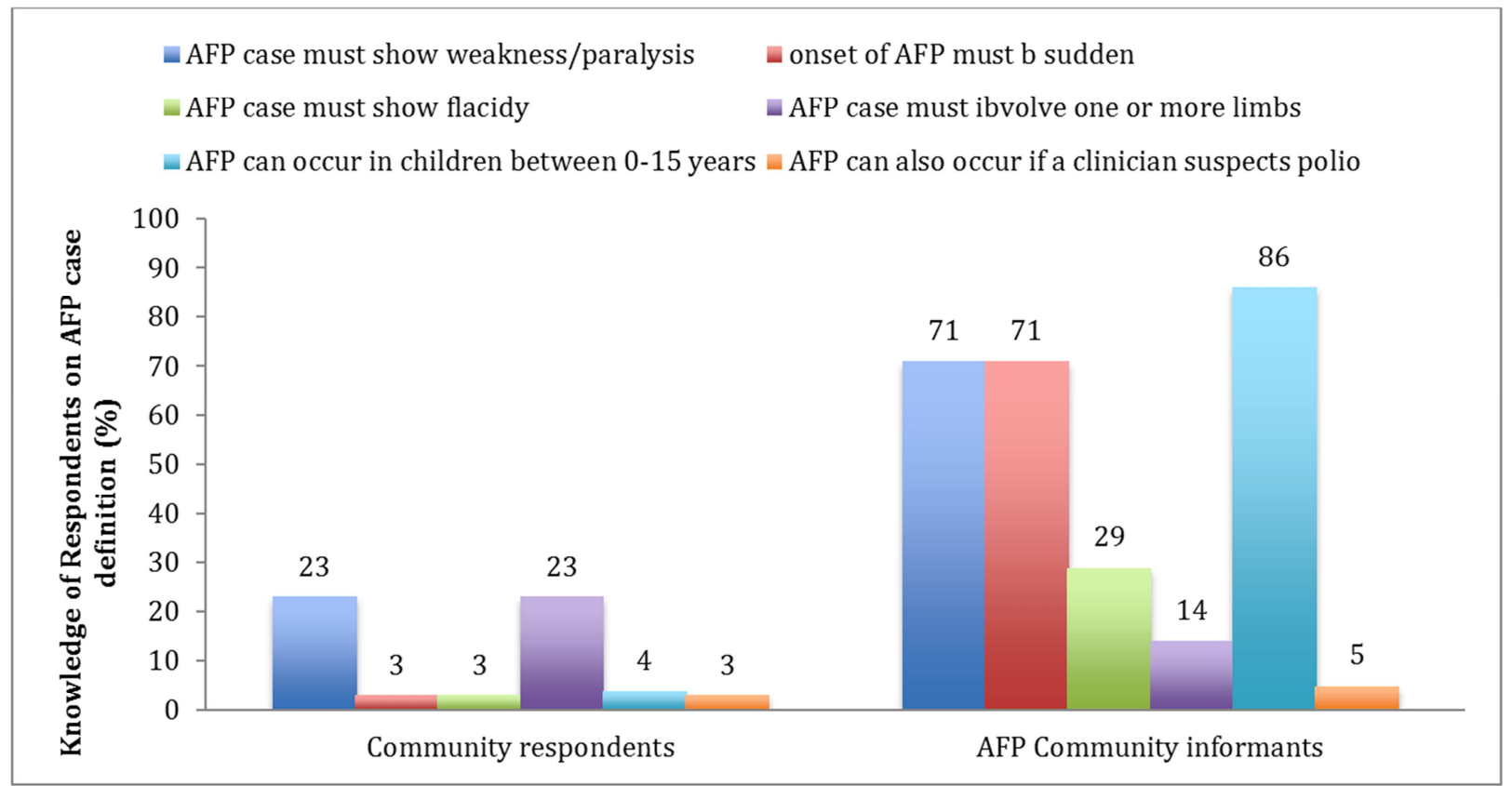

Figure 1. Knowledge of LGA Respondents on AFP case definition.

All, 427 respondents (community members $=420$, community informants $=7$ ) participated in this study. Figure 1 assesses the knowledge of these respondents on the AFP definition.

Among the community members $23.1 \%, 3 \%, 3 \%, 23.1 \%$, $3.5 \%$ and $3 \%$ respectively identified weakness/paralysis, sudden onset, flaccidity, involvement of one or more limbs, less than 15 years of age and a person of any age in which clinicians suspect polio as AFP standard case definition. On the average, $10 \%$ of the community members could identify the various aspects of the AFP case definition.

Among community informants, $71.4 \%$ identified weakness/paralysis and sudden onset, $28.6 \%$ identified flaccidity, $14.3 \%$ identified involvement of one or more limbs, $85.7 \%$ recognized the inclusion of a person less than 15 years of age and none identified that a person of any age in which clinicians suspect polio are parts of AFP standard case definition. On the average, $46 \%$ of the informants could identify correct and complete aspects of the AFP case definition.

Awareness of AFP surveillance by the community members and informants were assessed next in table 1. Majority of the community members weren't aware of AFP surveillance neither were they aware of their AFP focal person/DSNO or where to report AFP cases. Majority of the community members also didn't have the contact numbers of their AFP focal persons.

The community informants however were $100 \%$ aware of AFP surveillance, importance of reporting AFP cases, where to report these cases and had received refresher AFP training in the past year

The major barriers to AFP case reporting were assessed in Table 2. No case of AFP had been reported in the past 6 months. Reasons identified were irregular movements of commercial vehicles, swampy roads during rainy seasons, rocky roads during dry seasons; poor communication networks; and poor modes of transportation. 


\section{Discussion}

In this paper some the challenges to a sensitive AFP surveillance system along international border communities were identified and discussed. These include irregular movements of commercial vehicles, swampy roads during rainy seasons, rocky roads during dry seasons; poor communication networks; and poor modes of transportation. A weak AFP surveillance system constitutes a major threat to Nigeria's achieving a polio free certification status. This study investigates the factors that have affected AFP surveillance, case detection along the international border settlements of Oyo state, Nigeria.

The AFP surveillance system in the country is structured in such a way that case detection emanates from the community through well trained community informants making these group of people the backbone for AFP surveillance at the community/grass root level. [15]. Information about AFP cases pass through these group of people to the Disease Surveillance and Notification Officers (DSNOs) in the LGA and then to WHO surveillance officers in the state for prompt action. Because of their importance in the chain of event of AFP surveillance, WHO requires that these group of people must be well known givers of care in their communities such patent Medicine vendor owners, Bone setters, traditional healers etc. [16]. This makes them the first port of call whenever there is an issue with AFP case detection and surveillance in the communities.

From our results, it was observed that the community informants had fairly good knowledge of the AFP case definition. On the average $46 \%$ of the informants knew all the aspects of the AFP case definition, indicating incomplete knowledge of the AFP case This disagrees with a finding in Kaduna state (northern Nigeria) where all the community informants had very knowledge of all the aspects of the AFP case definition. [17]. The presence of more a sophisticated surveillance system in the north in comparison to the south due to the high probability of poliomyelitis in such areas must have accounted for this variation [18].

The more surprising detail here was that majority of the community members were not conversant with the AFP definition, neither were they aware of AFP surveillance. This correlates with another finding in in Gokwe North district, a rural district in Zimbabwe, which identified that there was poor awareness on AFP surveillance in the rural area of that district [19]. Poor community awareness defeats the purpose of the community informants because their mandate is not just to report cases but help educate members of their communities on AFP case pointers to look for in their communities. But a situation where even the informant lack complete knowledge of the AFP case definition themselves as per our study, it would be impossible to interact effectively with members of their communities. Hence, we recommend more frequent refresher trainings for these informants to improve the chances of AFP case reporting.

Results also show poor engagement between the community members and AFP focal person situated at the health facility whose job is to serve as an AFP contact point in the health facilities reporting directly to the DSNOs and the DSNOs themselves. We advise more frequent surveillance visits to these areas by DSNOs to encourage the informants by means of informal refresher training, which should help improve AFP case detection in their communities.

However these informants haven't reported cases of AFP in the past 6 months as per our result. Besides inadequate knowledge, which accounts for some of the problems with underreporting of AFP cases, we believe that the major problems affecting case detection and reporting lies with the terrain and funding. As per our results, informants cited Bad road terrain, which affects irregular movements of commercial vehicles, swampy roads during rainy season, and rocky roads during dry season; Poor communication network; Modes of transportation (which involves Four-wheel Drive to access the settlements) as threats hindering the reporting of AFP cases in their communities. This agrees with a similar finding in Borno state Nigreia where settlements were scattered as a result of the insurgency [20]. Some informants even companied that they weren't been given the funds as incentive given to them for reporting AFP cases.

Regarding the issues of withheld incentive, we encourage the DSNOs to always remit monies accruable to the informants as at when due to encourage them to report more cases. On the issue of terrain, we advocate suggest that adequate means of transportation to be provided to the informants to cater to enable them effectively reach the members of the communities. We also recommend that a special stipend be allocated to LGAs with border communities to enable them frequently carry out surveillance visits and mount sensitization campaigns that would not only improve knowledge of the community members but would also improve AFP case detection and reporting.

Contacting the DSNOs in situations where they are suspected AFP cases might be a bit tricky in these areas because poor telecommunication network challenges as stated in our study but as an alternative measure, we suggest that messages of case detection be passed on the DSNOs through the head of facilities who come to the LGA offices /cold stores to collect vaccines fortnightly. This doesn't solve the time-lag problem but it should reduce it to the minimum until the Government can provide adequate means of telecommunication in these border communities.

\section{Conclusion}

For the state to build a successful, resilient and sensitive AFP surveillance system, there is urgent NEED to tackle the difficult terrain along these international boarders that has greatly hindered surveillance activities in their corresponding communities. If steps are taken to improve accessibility in such areas, we believe that AFP case detection and reporting would also improve. 


\section{Authors' Contributions}

OOK, MMO, BEB, LIO, and AOA, JMI, OSO, contributed to the study design, interpretation of results, and manuscript conceptualization and preparation. FB SGT, BF, $\mathrm{BEB}$, data management and interpretation, and manuscript conceptualization and preparation. BEB and AOO contributed to the study design and manuscript preparation. All authors read and approved the final manuscript.

\section{Ethics Approval and Consent to Participate}

The consultation of an ethics committee and consent to participate is not required for analyses based solely on secondary data.

\section{Competing Interests}

The authors declare that they have no competing interests.

\section{Acknowledgements}

We wish to acknowledge the tireless and selfless effort of the personnel at the state and LGA levels; Omowele Adekumbi Fumilayo, Moshood Busari Babatunde, Egbe Eja Egbe.

\section{References}

[1] Bassey BE, Braka F, Vaz RG, Komakech W, Maleghemi ST, Koko R, et al. The global switch from trivalent oral polio vaccine (tOPV) to bivalent oral polio vaccine (bOPV): facts, experiences and lessons learned from the south-south zone; Nigeria, April 2016. BMC Infect Dis [Internet]. 2018 Dec 27 [cited 2019 Jan 8]; 18 (1): 57. Available from: https://bmcinfectdis.biomedcentral.com/articles/10.1186/s128 79-018-2963-6.

[2] Wen N, Fan C-X, Fu J-P, Ning J, Ji Y-X, Luo H-M, et al. Enhanced surveillance of acute flaccid paralysis following importation of wild poliovirus in Xinjiang Uygur Autonomous Region, China. BMC Infect Dis [Internet]. 2014 Jan [cited 2015 Jul 30]; 14 (1): 113. Available from: http://www.biomedcentral.com/1471-2334/14/113.

[3] Bassey BE, Fiona B, Muluh TJ, William K, Toritseju MS, Richard KI, et al. Assessment of the Quality of the Reverse Cold Chain Management in the Acute Flaccid Paralysis (AFP) Surveillance System for Polio Eradication; South-south Zone, Nigeria 2015. Am J Epidemiol Infect Dis Vol 4, 2016, Pages 100-104 [Internet]. 2016 Nov 14 [cited 2017 Nov 8]; 4 (5): 100-4. Available from: http://pubs.sciepub.com/ajeid/4/5/3/index.html.

[4] WHO | Immunization coverage reaches $84 \%$, still short of $90 \%$ goal. WHO [Internet]. 2014 [cited 2019 Jan 3]; Available from: https:/www.who.int/immunization/newsroom/press/immunizatio n_coverage_july2014/en/.

[5] WHO | Global eradication of polio: the case for "finishing the job." WHO [Internet]. 2011 [cited 2019 Jan 8]; Available from: https://www.who.int/bulletin/volumes/85/6/06- 037457/en/.

[6] Bandyopadhyay AS, Garon J, Seib K, Orenstein WA. Polio vaccination: past, present and future. Future Microbiol [Internet]. 2015 May 31 [cited 2019 Jan 8]; 10 (5): 791-808. Available https://www.futuremedicine.com/doi/10.2217/fmb.15.19.

[7] WHO | Global Strategy for Women's, Children's and Adolescent's Health \&amp; Every Woman Every Child Initiative. WHO [Internet]. 2017 [cited 2017 Jul 7]; Available from: $\quad$ http://www.who.int/life-course/partners/globalstrategy/en/.

[8] Tangermann RH, Lamoureux C, Tallis G, Goel A. The critical role of acute flaccid paralysis surveillance in the Global Polio Eradication Initiative. Int Health [Internet]. 2017 May 1 [cited 2019 Jan 8]; 9 (3): 156-63. Available from: http://www.ncbi.nlm.nih.gov/pubmed/28582560.

[9] WHO | Polio eradication initiative. WHO [Internet]. 2015 [cited 2019 Jan 8]; Available from: https://www.who.int/countries/eth/areas/immunization/pei/en/i ndex2.html.

[10] OPV Cessation - GPEI [Internet]. [cited 2017 Jun 8]. Available from: http://polioeradication.org/poliotoday/preparing-for-a-polio-free-world/opv-cessation/.

[11] Gardner TJ, Diop OM, Jorba J, Chavan S, Ahmed J, Anand A. Surveillance to Track Progress Toward Polio Eradication Worldwide, 2016-2017. MMWR Morb Mortal Wkly Rep [Internet]. 2018 Apr 13 [cited 2019 Jan 8]; 67 (14): 418-23. Available from: http://www.cdc.gov/mmwr/volumes/67/wr/mm6714a3.htm?s cid $=$ mm6714a3_w.

[12] Joel Adegoke O, Takane M, Biya O, Ota M, Murele B, Mahoney F, et al. Strengthening the Acute Flaccid Paralysis (AFP) Surveillance Compo-nent of the Polio Eradication Initiative through Short Message Service (SMS) Reminders; Experience from Sokoto State, Nigeria 2014 [Internet]. Journal of Immunological Sciences Research Article. 2014 [cited 2019 Jan 8]. Available from: http://www.immunologyresearchjournal.com/articles/strengthen ing-the-acute-flaccid-paralysis-afp-surveillance-component-ofthe-polio-eradication-initiative-through-short-message-ser.pdf.

[13] Dept PE, Organization WH, Geneva, Switzerland, Diseases D of V, Diseases NC for I and R, et al. Evaluating Surveillance Indicators Supporting the Global Polio Eradication Initiative, 2011-2012. MMWR Morb Mortal Wkly Rep [Internet]. 2013 [cited 2019 Jan 8]; 62 (14): 270. Available from: https://www.ncbi.nlm.nih.gov/pmc/articles/PMC4604901/.

[14] Umeh GC, Shuaib F, Musa A, Tegegne SG, Braka F, Mkanda $\mathrm{P}$, et al. Acute flaccid paralysis (AFP) surveillance intensification for polio certification in Kaduna state, Nigeria: lessons learnt, 2015-2016. BMC Public Health [Internet]. 2018 Dec 13 [cited 2019 Jan 8]; 18 (Suppl 4): 1310. Available from: http://www.ncbi.nlm.nih.gov/pubmed/30541509.

[15] Shuaib FMB, Musa PF, Gashu ST, Onoka C, Ahmed SA, Bagana M, et al. AVADAR (Auto-Visual AFP Detection and Reporting): demonstration of a novel SMS-based smartphone application to improve acute flaccid paralysis (AFP) surveillance in Nigeria. BMC Public Health [Internet]. 2018 Dec 13 [cited 2019 Jan 8]; 18 (S4): 1305. Available from: https://bmcpublichealth.biomedcentral.com/articles/10.1186/s 12889-018-6187-x. 
[16] Omoleke SA, Tadesse MG, Raji MT, Kende MA, Baba-Gana MA, Fiona B. The Role of Enabling and Motivating Factors in the Sustenance of Good Performance in Acute Flaccid Paralysis Surveillance in Kebbi State, Nigeria. Ann Med Health Sci Res [Internet]. [cited 2019 Jan 9]; Available from: https://www.amhsr.org/articles/the-role-of-enabling-andmotivating-factors-in-the-sustenance-of-good-performance-inacute-flaccid-paralysis-surveillance-in-kebbi-4358.html.

[17] Hamisu AW, Johnson TM, Craig K, Fiona B, B R, a, et al. Sensitivity of Acute Flaccid Paralysis Surveillance in Nigeria (2006-2015). J Infect Dis Treat [Internet]. 2016 Aug 6 [cited 2017 Nov 8]; 02 (02). Available from: http://infectiousdiseases-and-treatment.imedpub.com/sensitivity-of-acuteflaccid-paralysis-surveillance-in-nigeria20062015.php?aid=9975.

[18] Miller MA, Sentz JT. Vaccine-Preventable Diseases [Internet].
World Bank; 2006 [cited 2015 Aug 26]. Available from: http://www.ncbi.nlm.nih.gov/books/NBK2284/.

[19] Makoni A, Chemhuru M, Gombe N, Shambira G, Juru T, Bangure D, et al. Evaluation of the acute flaccid paralysis (AFP) surveillance system, Gokwe North district, Zimbabwe, 2015: a descriptive cross sectional study. Pan Afr Med J [Internet]. 2017 [cited 2019 Jan 8]; 27. Available from: http://www.panafrican-med-

journal.com/content/article/27/203/full/.

[20] Muzondo M, Shamu A, Shambira G, Gombe NT, Juru TP, Tshimanga M. Evaluation of the acute flaccid paralysis (AFP) surveillance system in Mwenezi district, Masvingo, 2018: a descriptive study. BMC Res Notes [Internet]. 2018 Dec 10 [cited 2019 Jan 9]; 11 (1): 875. Available from: https://bmcresnotes.biomedcentral.com/articles/10.1186/s1310 4-018-3981-6. 